\title{
А.И. Глухов ${ }^{1,2}$, Д.А. Сивохин ${ }^{1}$, Д.А. Серяк ${ }^{1}$, Т.С. Родионова ${ }^{1}$, М.И. Камынина ${ }^{1}$
}

${ }^{1}$ Первый Московский государственный медицинский университет имени И.М. Сеченова

(Сеченовский Университет), Москва, Российская Федерация

${ }^{2}$ Московский государственный университет имени М.В. Ломоносова, Москва, Российская Федерация

\section{Онколитические вирусы}

\section{как иммунотерапевтические агенты в лечении злокачественных новообразований}

Онколитические вирусы представляют собой стремительно развивающийся класс терапевтических агентов для борьбы со злокачественными новообразованиями, которые позволяют эффективно инфицировать и разрушать опухолевые клетки, оставляя интактными здоровые ткани. Многие вирусы обладают естественной противоопухолевой активностью, вызывая ицтолиз раковых клеток за счет прямого патогенного действия. Однако наряду с неиммуногенной клеточной гибелью онколитические вирусы способны индуцировать иммуногенные формы клеточной смерти (иммуногенный апоптоз, пироптоз и др.), сопровождающиеся высвобождением из опухолевых клеток DАMPs (молекулярных паттернов, ассоциированных с повреждением) и ТААs (опухольассоцированных антигенов), что приводит к активации адаптивного противоопухолевого иммунного ответа. Естественная активация иммунитета в результате вирусной инфекции оказывается, однако, недостаточно эффективной для уничтожения опухоли, что может быть решено путем создания генно-модифицированных итаммов различных вирусов, в которые встраиваются иммуностимулирующие трансгены: гранулоцитарно-макрофагальный колониестимулирующий фактор (GM-CSF), интерлейкины (IL2, 15, 12), ТАА или костимулирующие лиганды (CD), а также используется подход «рriте-bооst», что дополнительно повыщает безопасность и эффективность онколитической виротерапии. Предварительные результаты рандомизированных клинических испытаний рекомбинантных онколитических вирусов с повышенной иммуногенностью подтверждают их эффективность, однако для создания полноценных препаратов для онкотерапии на основе онколитических вирусов требуется дальнейшая оптимизация этих подходов.

Ключевые слова: онколитические вирусы, онколитическая виротерапия, иммунотерапия, опухольассоциированные антигены.

(Для цитирования: Глухов А.И., Сивохин Д.А., Серяк Д.А., Родионова Т.С., Камынина М.И. Онколитические вирусы как иммунотерапевтические агенты в лечении злокачественных новообразований. Вестник PAMH. 2019;74(2):108-117. doi: 10.15690/vramn1091)

\section{Введение}

Вирусный онколиз представляет собой принципиально новый метод лечения злокачественных новообразований.

Способностью размножаться преимущественно в злокачественно трансформированных клетках обладает ряд природных вирусов, ослабленные штаммы которых непатогенны для людей. Доклинические и клинические исследования онколитических вирусов - инфекционных агентов, способных вызывать избирательную гибель опухолевых клеток, - уже показали высокую эффективность в лечении ряда онкологических заболеваний при сравнительно малой токсичности [1].

Однако более перспективным является использование онколитических вирусов как платформы для иммунотерапии злокачественных новообразований. Так, в настоящее время созданы рекомбинантные штаммы онколитических вирусов с целью повышения их онкоселективности и иммуногенности [2].

\section{A.I. Glukhov ${ }^{1,2}$, D.A. Sivokhin ${ }^{1}$, D.A. Seriak ${ }^{1}$, T.S. Rodionova ${ }^{1}$, M.I. Kamynina ${ }^{1}$}

${ }^{1}$ I.M. Sechenov First Moscow State Medical University (Sechenov University), Moscow, Russian Federation ${ }^{2}$ M.V. Lomonosov Moscow State University, Moscow, Russian Federation

\section{Oncolytic Viruses As Immunotherapeutic Agents for the Treatment of Malignant Tumors}

Oncolytic viruses $(\mathrm{OVS})$ are novel and rapidly developing class of therapeutic agents for combating cancer, which can effectively infect and destroy tumor cells, leaving healthy tissues intact. Many viruses have a natural antitumor activity which causes cytolysis of cancer cells due to direct pathogenic action. Along with non-immunogenic cell death, oncolytic viruses have been shown to be capable of inducing immunogenic cancer cell death (necrosis, pyroptosis, etc.) accompanied by the release of OV-lysed tumor-associated antigens (TAAs). Releasing DAMPs and TAAs, in its turn, leads to the activation of adaptive antitumor immunity. In order to further enhance the antitumor immunity, OVs have been armed with immunostimulatory transgenes such as granulocyte-macrophage colony-stimulating factor (GM-CSF), type I interferons, interleukins (IL-2, 12, 15), costimulatory ligands (CD40, CD80), tumor antigens («prime-boost» vaccination), which further enhances the safety and effectiveness of oncolytic virotherapy. Preliminary results of randomized clinical trials of different approaches of oncolytic virotherapies in combination with immunotherapy confirm their high efficacy. However, there are some drawbacks, which necessitates their further study.

Key words: oncolytic viruses, oncolytic virotherapy, immunotherapy, tumour-associated antigen.

(For citation: Glukhov AI, Sivokhin DA, Seriak DA, Rodionova TS, Kamynina MI. Oncolytic viruses as immunotherapeutic agents for the treatment of malignant tumors. Annals of the Russian Academy of Medical Sciences. 2019;74(2):108-117. doi: 10.15690/vramn1091) 
Еще в начале XX в. впервые было замечено, что вирусные инфекции могут вызывать ремиссию онкологических заболеваний $[1,3]$. Одним из первых вирусов, с которым было проведено доклиническое исследование на животных моделях, стал вирус дальневосточного энцефалита. Результатом исследования было полное уничтожение опухолевых клеток, но вирусная инфекция вызвала тяжелые побочные эффекты [4].

Первое успешное применение онколитической виротерапии было связано с послеоперационным применением вируса болезни Ньюкасла, при этом удалось стимулировать многолетнюю ремиссию заболевания у пациентов со II стадией злокачественной меланомы [5].

С 1950 по 1980 г. исследования в этой области проводились на природных штаммах вирусов, в первую очередь на вирусе герпеса [3], но темпы развития онковиротерапии в эти годы были замедлены ввиду неполного понимания осложнений и отсутствия терапевтического эффекта у многих пациентов из-за развития противовирусного иммунитета. Настоящий прорыв в области виротерапии опухолей связан с развитием генной инженерии и созданием рекомбинатных вирусов, способных не только более избирательно уничтожать раковые клетки, но и стимулировать собственный противоопухолевый иммунитет.

В 1981 г. был создан первый рекомбинантный штамм вируса на основе вируса герпеса HSV-1. В нем были удалены гены, отвечающие за презентацию антигенов в главном комплексе гистосовместимости и поддерживающие распространение вируса в здоровых клетках [6].

Первым онколитическим вирусом, одобренным в клинической практике, стал ослабленный штамм вируca ECHO 7-го типа. Препарат на основе этого вируса под названием Rigvir для адъювантного лечения меланомы путем внутримышечного введения применяется с 2004 г. в Латвии [7]. Однако отсутствие регистрации в Европейском агентстве лекарственных средств и крупных рандомизированных исследований данного препарата не дают возможности в настоящее время объективно оценить его эффективность.

В 2006 г. в Китае был официально разрешен к применению в клинической практике новый препарат Oncorine (H101), созданный на основе генетически модифицированного аденовируса, разработанного для лечения рака пищевода, шеи и головы $[1,3]$. Однако он так же не получил широкого применения.

Наиболее современный препарат Talimogene laherparepvec (T-Vec), представляющий собой модифицированный вирус простого герпеса человека 1-го типа (HSV-1), был одобрен Управлением по санитарному надзору за качеством пищевых продуктов и медикаментов (Food and Drug Administration, FDA) в 2015 г. для лечения метастатической меланомы [8]. Более подробно о нем будет сказано ниже.

В 2018 г. нобелевская премия присуждена ученым Тасуку Хондзё и Джеймсу Эллисону за открытие онкотерапии путем ингибирования иммунных контрольных точек, к которым относятся белки PDL-1 (programmed cell death ligand 1), экспрессирующийся в опухоли, и CTLA-4 (cytotoxic T-lymphocyte-associated protein 4), образующийся на поверхности Т-клеток. Данные белки подавляют активность иммунной системы организма, ингибируя пролиферацию и цитотоксическую активность Т-лимфоцитов [9]. На основании этих исследований в 2011 г. было одобрен препарат для лечения меланомы Ипилимумаб - антитело, блокирующее CTLA-4. Позднее, в 2014 г., появился Ниволумаб, предназначенный для борьбы с меланомой, раком легкого, почки и рядом других онкопатологий.

В течение 10 лет количество клинических исследований с использованием генетически модифицированных онколитических вирусов резко возросло, однако за последние 4 года не наблюдалось появления новых действующих препаратов, что, вероятно, связано с процессом накопления научных знаний в молекулярной генетике опухолей и онкоиммунологии. В будущем, возможно, именно комбинации молекулярно-генетических и иммунологических подходов в лечении онкологических заболеваний приведет к повышению эффективности онколитической вирусотерапии.

В данном обзоре мы приводим все известные механизмы действия онколитических вирусов и эффективность применения их диких штаммов, а также все последние клинически значимые достижения использования онколитических вирусов как самостоятельного методологического подхода к лечению при усилении иммуногенности модифицированных онколитических вирусов.

При подготовке статьи был выполнен анализ релевантных статей в базах данных Medline, Scopus, Web of Science, опубликованных в период с 2012 по 2018 г., а также клинических исследований в реестре ClinicalTrials. gov. с использованием тематических рубрик и ключевых слов «оncolytic viruses», «viral oncolysis», «virotherapy», «oncolytic immunotherapy». Исключением из обзора были исследования, в которых использовались химиотерапевтические препараты отдельно или совместно с онколитическими вирусами.

\section{Механизмы селективности действия онколитических вирусов}

Вирусы, обладающие естественными онколитическими свойствами, используют неисправные противовирусные пути или специальные белки, экспрессирующиеся в опухолевых клетках, для избирательного размножения в клетках опухоли. Модифицированные вирусы содержат гены, повышающие их тропизм к опухолевым клеткам и репликацию в них.

Существует несколько подходов для создания опухолевой селективности генетически модифицированных онколитических вирусов. Например, в $85 \%$ опухолевых клеток экспрессируется ген $h T E R T$, кодирующий каталитическую субъединицу теломеразы человека. В результате встраивания в геном вируса гена $E 1$, который экспрессируется под действием данной субъединицы теломеразы, увеличивается активность онколитических вирусов только в опухолевых теломеразапозитивных клетках. В 2007 г. теломеразаспецифический репликационно-селективный аденовирус (TRAD) прошел I фазу испытаний, однако противоопухолевая активность исследовалась на небольшой выборке пациентов [10].

Одним из существенных препятствий к безопасности и эффективности системного лечения онкологических заболеваний является невозможность увеличения лечебной дозы онколитического вируса, в частности аденовируса, из-за его дозозависимой гепатотоксичности. Данное ограничение в терапевтической дозе может быть расширено благодаря изменению вирусного белка, отвечающего за связь с клеткой и за проникновение в нее [10]. Например, аденовирусный капсидный белок гексон, связанный с фактором X свертывания крови, был признан главным белком-активатором трансдукции 
гепатоцитов [11]. В исследовании E. Shashkova и соавт. [11] вводили пептид — акцептор биотина (ВАР), состоящий из 75 аминокислот, в гипервариабельную цепь 5 (Ad5) гексона, что в последствии ослабляло его связь с фактором Х в 10000 раз, уменьшало повреждение печени, позволяло направить большее количество онколитических вирусов к опухоли и увеличить терапевтическую дозу вируса в 10 раз. Известно, что в опухолевых клетках часто повышена активность RAS-зависимого сигнального пути. В связи с этим третий подход заключается в повышении эффективности репликации вируса путем создания измененного HSV-1 с экспрессией белка ICP4 (инфицированный клеточный белок-4, необходимый для репликации вируса), активация экспрессии которого находится под контролем транскрипционного фактора ELK, являющегося незаменимым участником RAS-пути. Таким образом, модифицированный HSV-1 преимущественно может размножаться в клетках с повышенным уровнем вышеупомянутого фактора транскрипции, что обеспечивает селективное воздействие вируса на опухолевые клетки [10].

\section{Механизмы вирусного онколиза}

Существуют различные механизмы вирусного онколиза, которые зависят от структуры вируса и закодированного в его геном трансгена. Однако существуют общие принципы, которые большинство онколитических вирусов использует для достижения противоопухолевого эффекта [12]. Онколиз, как правило, проходит в 2 стадии [13].

В первой фазе (прямой) происходит гибель опухолевой клетки за счет цитолитического действия вируса или за счет активации противовирусного иммунитета в ответ на внедрение патогена в опухолевые клетки [13]. Этот процесс сопровождается высвобождением сигналов, связанных с повреждением молекулярного паттерна (damage associated molecular patterns, DAMP), и пула опухольассоциированных антигенов (tumor-associated antigens, TAAs) [14].

Вторая фаза (непрямая) связана с процессом кросспраймирования и включает в себя индукцию как специфического, так и неспецифического противоопухолевого иммунитета [12], а именно распознавание сигнальных молекул (прежде всего TAAs) антигенпрезентирующими клетками (АРС), которые представляют их в составе основного комплекса гистосовместимости (major histocompatibility complex, MHC) I класса (MHC I) CD8+ Т-клеткам и в комплексе MHC II - CD4+ Т-хелперам в сочетании с костимулирующими молекулами и цитокинами, активирующими Т-клетки [14].

Таким образом, онколитические вирусы могут вызывать как иммуногенную, так и неиммуногенную гибель опухолевых клеток. Среди различных видов клеточной смерти, запускаемых онколитическими вирусами, - некроз, апоптоз, некроптоз, пироптоз и аутофагия (табл. 1).

Таблица 1. Виды клеточной гибели, запускаемые онколитическими вирусами

\begin{tabular}{|c|c|c|c|c|}
\hline $\begin{array}{c}\text { Вид клеточной } \\
\text { гибели }\end{array}$ & $\begin{array}{c}\text { Онколитический вирус, } \\
\text { индуцирующий клеточную } \\
\text { гибель }\end{array}$ & Механизм воздействия & Иммуногенный компонент & Источник \\
\hline \multirow{5}{*}{ Апоптоз } & $\begin{array}{l}\text { Вирус везикулярного } \\
\text { стоматита (VSV) }\end{array}$ & Экспрессия IFN $b$ & HMGB1, кальретикулин & {$[15,16]$} \\
\hline & Вирус Ньюкасла & $\begin{array}{l}\text { Связывание с клеткой через } \\
\text { гемагглютинин-нейраминидазу (HN) }\end{array}$ & $\begin{array}{l}\text { TAAs, HMGB1, } \\
\text { кальретикулин, белки } \\
\text { теплового шока 70/90 }\end{array}$ & {$[16-18]$} \\
\hline & Аденовирус TNF $\alpha$ (IL2) & $\begin{array}{l}\text { Использование неисправных сигнальных } \\
\text { путей р16/Rb }\end{array}$ & $\begin{array}{l}\text { TNF } \alpha \text { и/или IL2 (в } \\
\text { зависимости от оснащения) }\end{array}$ & {$[16,19]$} \\
\hline & Реовирус & $\begin{array}{l}\text { Дефект РНК-зависимой протеинкиназы. } \\
\text { Активация сигнального пути RAS или } \\
\text { мутация белков-эффекторов, приводящая } \\
\text { к снижению IFN-индуцированного } \\
\text { антивирусного иммунного ответа. } \\
\text { Дисфункция или делеция опухолевых } \\
\text { генов-супрессоров (р53 и т.д.) }\end{array}$ & PAMPS & {$[16,20,21]$} \\
\hline & Вирус кори & $\begin{array}{l}\text { Проникает в клетку через } \\
\text { взаимодействие с CD46 и сигнальную } \\
\text { лимфоцитактивирующую молекулу } \\
\text { (SLAM), через протеин F приводит к } \\
\text { слиянию клеток и образованию синцития }\end{array}$ & HMGB1, CXCL10 & {$[16,18]$} \\
\hline \multirow[b]{3}{*}{ Аутофагия } & Вирус Ньюкасла & $\begin{array}{l}\text { Связывание с клеткой через } \\
\text { гемагглютинин-нейраминидазу (HN) }\end{array}$ & $\begin{array}{l}\text { HMGB1, кальретикулин, } \\
\text { белки теплового шока 70/90 }\end{array}$ & {$[16,17,20]$} \\
\hline & Аденовирус & $\begin{array}{l}\text { Использование неисправных сигнальных } \\
\text { путей р16/Rb }\end{array}$ & $\begin{array}{l}\text { TAАs, аденозинтрифосфат, } \\
\text { кальретикулин, HMGB1, } \\
\text { мочевая кислота }\end{array}$ & {$[16,22]$} \\
\hline & Реовирус & $\begin{array}{l}\text { Дефект РНК-зависимой протеинкиназы. } \\
\text { Активация сигнального пути RAS или } \\
\text { мутация белков-эффекторов, приводящая } \\
\text { к снижению IFN-индуцированного } \\
\text { антивирусного иммунного ответа. } \\
\text { Дисфункция или делеция опухолевых } \\
\text { генов-супрессоров (р53 и т.д.) }\end{array}$ & PAMPs & {$[16,20,21]$} \\
\hline
\end{tabular}


Таблица 1. Виды клеточной гибели, запускаемые онколитическими вирусами (Окончание)

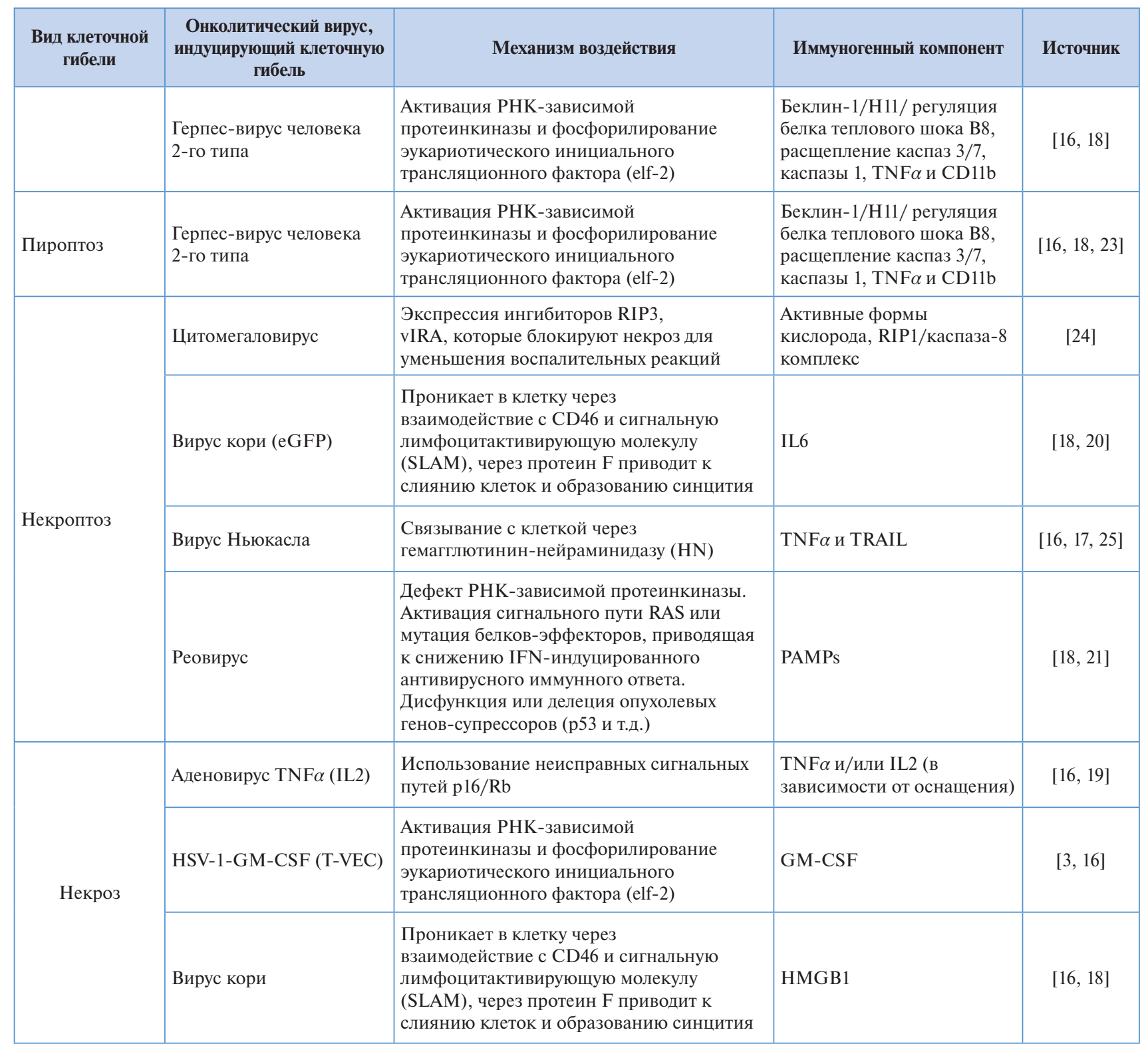

\section{Апоптоз}

Апоптоз в основном характеризуется потерей целостности митохондриальной мембраны, активацией каспаз и образованием апоптотических телец [24]. Появление фосфатидилсеринов на наружной стороне клетки во время апоптоза облегчает удаление апоптотических тел фагоцитами без индукции воспаления [24]. Этот процесс обычно сопровождается высвобождением противовоспалительных цитокинов для минимизации побочного повреждения, что необходимо для нормального развития и гомеостаза тканей [24], поэтому апоптотическая гибель клеток считается неиммуногенной и невоспалительной по своей природе [26]. Однако по результатам недавних исследований было выявлено, что если обработать опухолевые клетки определенными цитостатиками [27], такими как антрациклины и препараты платины [24], то на их поверхности до начала апоптоза обнажаются кальретикулин и белки теплового шока [27].

Аналогичные процессы наблюдаются при действии онколитических вирусов на опухолевые клетки. Под их действием активируются процессы, связанные с транспортом кальретикулина (ecto-CRT) на поверхность клеточной мембраны, который совместно с ERP57 участвует в транспорте белка МНС I для связывания антигена и последующего представления на клеточной поверхности с целью индукции иммуногенного апоптоза и последующего высвобождения жизненно важных DAMP для дальнейшего развития противоопухолевых иммунных ответов [26].

На более поздних стадиях иммуногенного апоптоза другие DAMP, такие как HMGB1, высвобождаются из погибающих раковых клеток и секретируются из активированных иммунных клеток [26], что также наблюдается при аутофагии и некрозе [20].

Одним из наиболее ярких примеров индукторов иммуногенного апоптоза является вирус болезни Ньюкасла - природный онколитический вирус, относящийся к роду Avulavirus, семейство Paramyxoviridae, известный также как птичий парамиксовирус 1-го типа [28]. Он избирательно реплицируется в человеческих опухолевых клетках, вызывает их иммуногенную клеточную гибель, не воздействуя на здоровые клетки. Такая селективность вируса доказана во многих научных экспериментах и обусловлена дефектами антивирусных и апоптотических сигнальных путей в раковых клетках [17]. 
Вирус болезни Ньюкасла способен индуцировать классический апоптоз благодаря связыванию фактора некроза опухоли с апоптозиндуцирующим лигандом (белок TRAIL) и активации каспаз, что приводит к открытию пор митохондриальной мембраны и снижению ее потенциала. Однако такой физиологический апоптоз неиммуногенен. Вирус болезни Ньюкасла может самостоятельно вызывать иммуногенный апоптоз, некроз и аутофагию. При этом происходят остановка синтеза белка, транслокация кальретикулина и белков теплового шока на плазматическую мембрану, высвобождение провоспалительных цитокинов и перекрестное представление опухолесодержащих антигенов, тем самым активируется иммуногенный противоопухолевый ответ [17]. U. Ahmad и соавт. исследовали множество штаммов вируса болезни Ньюкасла, однако наиболее эффективным оказался штамм AF 2240, на котором были доказаны такие свойства, как ингибирование клеточной пролиферации раковых клеток и клеточная миграция рака молочной железы, а также показана его эффективность в отношении глиобластомы и лейкоза [28].

Терапия данным вирусом хорошо переносится и имеет высокий профиль безопасности, что отмечается во многих исследованиях [17, 29]. В испытаниях В. Кешелавы и др. [29] был использован вирус болезни Ньюкасла в качестве неоадъювантной терапии при внутрикожном введении в область передней наружной стенки с интервалами 7-10 дней в течение 2-4 нед в зависимости от стадии заболевания. В группе больных раком молочной железы I-IIIb стадии за 3 года наблюдений безрецидивная выживаемость составила 97,8\%, общая выживаемость $100 \%$; в группе больных раком шейки матки I-IIIb стадии - 44,4 и 66,7\% соответственно. В исследовании были доказаны противоопухолевая активность вируса болезни Ньюкасла (выраженный патоморфоз опухоли у 54,4\% больных раком молочной железы) и иммуностимулирующее действие вируса (повышение уровней CD3, CD8 и CD19); также неоднократно указывалось на хорошую переносимость препарата и отсутствие влияния на сроки проведения хирургического лечения [29].

Поскольку рецепторы вируса болезни Ньюкасла экспрессируются на многих клетках, этот вирус потенциально может использоваться против широкого спектра опухолей [17].

\section{Аутофагия}

Аутофагия - процесс, при котором дефектные органеллы клеток устраняются с помощью лизосом. Исследования показали, что очищенные аутофагосомы могут функционировать как эффективные носители антигенов для перекрестной презентации [26], следовательно, аутофагия облегчает кросс-праймирование с целью получения ТАА-специфических или вирусоспецифических CD8+ T-клеток, что стимулирует обработку антигенов как для МНС II класса, так и для МНС I [20]. Кроме того, в процессе аутофагии клетки селективно выделяют DAMP, такие как аденозинтрифосфат (ATФ), HMGB1 и мочевую кислоту, что повышает иммуногенность опухоли [20]. Аутофагия способствует также поддержанию и функционированию нормальных гемопоэтических стволовых клеток и влияет на поляризацию Т-клеток, нацеливая различные их группы (в том числе регуляторные, T-regs) на определенные анатомические участки [27]. Таким образом, реакция на аутофагию меняется в зависимости от типа клеток и микроокружения опухоли [27].

\section{Пироптоз}

Пироптоз (или каспаза 1-зависимая клеточная гибель) характеризуется конденсацией хроматина и фрагментацией ДНК, набуханием мембраны, высвобождением мембранных везикул, разрывом мембраны и выходом DAMP из клеточной цитоплазмы $[17,26]$. Это очень иммуногенная форма клеточной смерти, опосредованная активацией каспазы-1 и выделением провоспалительных цитокинов [26]. Пироптотические и некротические клетки выделяют АТФ более эффективно, чем апоптотические тельца. Однако и пироптотические, и апоптотические клетки активно индуцируют фагоцитоз макрофагами с использованием сигналов «съесть меня» и «найти». Цитолитические иммунные клетки, привлеченные онколитическими вирусами или другими агентами, вызывают гибель дополнительного числа опухолевых клеток, приводя к высвобождению DAMP, таких как HMGB1 [20].

\section{Некроптоз}

Некроптоз (или запрограммированный некроз) функционирует в качестве резервного механизма, позволяющего элиминировать инфицированные клетки, которые не могут пройти апоптоз [24]. Исследования показывают, что некроптоз возможен и в опухолевых клетках [20]. Было продемонстрировано, что запрограммированный некроз при вакцинировании онколитическими вирусами связан с образованием комплекса RIP1-киназа/каспаза-8 [24]. В регуляции некроптоза участвуют сигнальный путь RIP3 и ген $C Y L D$, чей фермент непосредственно регулирует убиквитинирование RIP1 [20]. Особенности некротической гибели клеток, зависящих от RIP3, проявляются индукцией воспаления, улучшением представления антигена и эффективной защитой от патогена [24]. Несмотря на устойчивость некоторых видов рака к некроптозу из-за генетических и эпигенетических дефектов - это важный вид клеточной гибели для резистентных к апоптозу раков, вызываемый многими противоопухолевыми режимами [20]. Продемонстрировано, что высокоспецифичный ингибитор каспазы-8 vICA, кодируемый цитомегаловирусом, предопределяет RIP3-зависимый некроптоз, а ингибиторы апоптоза активируют TNFRзависимый некроптоз у вакцинированных вирусом коровьей оспы мышей [24].

\section{Некроз}

Некроз характеризуется увеличением объема клеток, отеком органелл, разрывом плазматической мембраны и последующей потерей внутриклеточного содержимого, включая HMGB1 и АТФ $[17,26]$, а также сопровождается высвобождением провоспалительных цитокинов, таких как фактор некроза опухоли $\alpha$ (tumor necrosis factor alpha, $\mathrm{TNF} \alpha$ ) и других иммуномодулирующих медиаторов гибели клетки [24].

Полагают, что вирусный онколиз сложен и не может включать в себя только один вид клеточной смерти. Это отчасти связано с тем, что онколитические вирусы останавливают гибель клетки до тех пор, пока клеточные ресурсы не будут полностью использованы для максимального производства вирусного потомства [12]. Например, реовирус в дополнение к апоптозу также может вызывать аутофагию и запрограммированный некроз, что, возможно, зависит от кровеносных сосудов, иммунных клеток, сигнальных молекул, окружающих клетку [21].

Немодифицированный непатогенный штамм реовиpyca Dearing 3-го типа, известный как препарат Реолизин, уже был исследован в доклинических и клиниче- 
ских (I и II фазах) испытаниях [30, 31]. И хотя препарат не был допущен ко второму этапу клинических исследований из-за отсутствия должной эффективности, тем не менее при его использовании путем внутривенного введения обнаружилась высокая способность к репликации реовируса при метастазах меланомы [31]. В опухолевых клетках нарушены сигнальные пути протеинкиназы R, что способствует выживаемости вируса. При участии рецептора эпидермального фактора роста вирус, проникая в клетку, активирует RAS-зависимый сигнальный путь, что позволяет ему инициировать трансляцию и репликацию.

В исследовании J. Carew и соавт. были обнаружены и другие механизмы действия данного вируса: он способен вызвать значительную индукцию антиангиогенного хемокина CXCL10 вне зависимости от статуса RAS, а также снизить уровень экспрессии факторов, индуцируемых гипоксией (hypoxia-inducible factors, HIF) - $1 \alpha$ и $2 \alpha$, и ингибировать секрецию фактора роста эндотелия сосудов (VEGF) [32]. Повышение уровня CXCL10 при действии Реолизина позволило улучшить противоопухолевое действие сунитиниба, бевацизумаба и гемцитабина, что послужило основанием к проведению дальнейших исследований реовируса в комбинации с химиопрепаратами или моноклональными антителами $[33,34]$.

Онколитические вирусы, в дополнение к онколизу инфицированных клеток, могут опосредовать гибель неинфицированных раковых клеток с помощью косвенных механизмов, включая разрушение опухолевых кровеносных сосудов, усиление специфических противораковых иммунных реакций или через специфическую активность трансгенных белков в генетически модифицированных вирусах.

\section{Стратегии усиления иммуногенности онколитических вирусов}

Существует множество современных стратегий, позволяющих усилить способность онколитических вирусов стимулировать противоопухолевый иммунитет.

\section{Встраивание в геном онколитических вирусов трансгена-иммуномодулятора}

Главным подходом к повышению противоопухолевого иммунитета с помощью онколитических вирусов стало встраивание в их геном различных трансгенов-иммуномодуляторов. Например, были разработаны онколитические вирусы с такими трансгенами, как гранулоцитарно-макрофагальный колониестимулирующий фактор (GM-CSF), интерферон $b$, интерлейкины (interleukin, IL) $2,15,12$, белки теплового шока [14], а также мембраносвязанные костимулирующие молекулы, такие как CD40 и CD80 [35]. Одним из самых эффективных подходов к увеличению иммунного ответа является оснащение вирусного вектора GM-CSF, который способен во много раз повысить цитотоксические иммунные реакции [10]. Эта стратегия была успешно применена при создании препарата T-Vec на основе вируса герпеса HSV-1 посредством внутриопухолевого введения для лечения метастатической меланомы. Эффективность Т-Vес оказалась наиболее выраженной у пациентов со стадией IIIb, IIIc или IVM1а и у пациентов, не получавших ранее лечения, что несколько ограничивает применение данного препарата в клинической практике [8].
Другой препарат, JX-594 (pexastimogene devacirepvec, Реха-Vec), состоит из онколитического вируса коровьей оспы с делецией генов тимидинкиназы и фактора роста [27], кодирующего GM-CSF [36]. Препарат продемонстрировал многообещающие результаты в I и II фазах клинических испытаний $[27,36]$, и в 2015 г. началась регистрация пациентов с распространенной стадией гепатоцеллюлярной карциномы для проведения испытаний фазы III [3]. Рандомизированное исследование фазы II показало увеличение медианы выживаемости для высоких доз по сравнению с низкими (14,1 против 6,7 мес соответственно) [37]. Преимуществом использования вируса осповакцины являются внутривенная стабильность для доставки, сильная цитотоксичность и обширный опыт безопасности в качестве живой вакцины [3]. Также для лечения гепатоцеллюлярной карциномы были проведены испытания Ib и II фазы осповакцины, в которой вирус экспрессировал трансгены (hGM-CSF, $\beta$-галактозидаза) в эндотелиальных клетках сосудов опухоли у людей. Исследования показали нарушение перфузии опухоли уже через 5 дней, при этом повреждений нормальных сосудов не наблюдалось [38].

Введение IL2 в качестве иммунотерапии одобрено FDA в 1985 г. Было обнаружено, что на фоне конститутивной экспрессии IL2 из онколитической вакцины происходит снижение специфического эффекта онколитических вирусов из-за уменьшения экспрессии вирусного гена в опухоли. При этом наблюдалось повышение общей активности вируса посредством экзогенной активирующей функции цитокина [39]. На данный момент перспективным является использование аденовируса, экспрессирующего IL2 и TNF $\alpha$. Испытания, проводимые на животных моделях опухоли человека, показали сильную противоопухолевую эффективность данного вектора, увеличение уровней CD4+ и CD8+ T-лимфоцитов in vivo, а также увеличение пролиферации спленоцитов ex vivo при приемлемом профиле безопасности [19].

IL12 является мощным провоспалительным цитокином с антиангиогенной активностью. Когда он экспрессируется онколитическим вирусом простого герпеса, то уменьшает неоваскуляризацию и количество регуляторных Т-клеток опухоли (T-reg) и индуцирует развитие Т-клеточного иммунитета в модели стволовых клеток $[2,27]$. Исследования вируса простого герпеса, экспрессирующего IL12, на моделях мышиного рака яичника и опухоли яичника человека продемонстрировали эффективный лизис новообразований и увеличение антигенспецифических CD8+ T-клеток, что приводило к уменьшению внутриперитонеальных метастазов и улучшению выживаемости в мышиной модели [40]. Кроме того, вирус простого герпеса с трансгеном IL12 был испытан в доклинических испытаниях на животных моделях злокачественной глиомы, где подтвердил свою безопасность при внутричерепной инокуляции, и в настоящий момент проходит клинические испытания фазы I у пациентов со злокачественной глиомой [41].

$\mathrm{K}$ средствам, уменьшающим сосудистую сеть опухоли, относится экспрессия антагониста CXCR4, являющегося рецептором хемокина CXCL12. Данный антагонист также приводит к накоплению эпителиальных и миелоидных клеток костного мозга и индуцирует противоопухолевые гуморальные реакции, формирующие устойчивость к рецидиву опухоли [2, 27]. Данный подход может оказывать значительное терапевтическое воздействие против первичного и метастатического рака молочной железы [42]. 
Не менее интересной является также возможность усилить кросс-презентацию опухолевых антигенов. В условиях клеточного стресса или некроза клетки продуцируют белки теплового шока (heat shock proteins, HSP), которые функционируют как молекулярные шапероны, приводя к перекрестному представлению опухолевых пептидов в комплексе с молекулами МНС I [26, 43]. Онколитические вирусы, экспрессирующие различные HSP, включая HSP70, HSP90, HSF1 и фактор транскрипции теплового шока, были исследованы на моделях меланомы и колоректальной карциномы. Данные исследования показали, что для неоадъювантной иммунотерапии более эффективным является HSF1, чем гены других белков теплового шока [44]. Клиническое исследование I фазы показало, что вакцина Н103, состоящая из онколитического аденовируса, экспрессирующего HSP70, при внутриопухолевом введении имеет хорошую эффективность и безопасность [45].

Одним из факторов, снижающих эффективность иммунотерапии в опухоли, является простагландин Е2 (PGE2). Вирусные векторы, сконструированные для таргетного действия на PGE2, способствовали преодолению локальной иммуносупрессии и приводили к изменению иммунного статуса опухоли, что позволило увеличить действие противоопухолевого адаптивного иммунного ответа [46].

\section{Встраивание в геном онколитических вирусов}

\section{опухольассоциированного антигена}

Несмотря на экспрессию раковыми клетками опухольассоциированных антигенов, зачастую иммунная система к ним толерантна. Кроме того, микроокружение опухоли обладает иммуносупрессивными свойствами, что создает дополнительную защиту от иммунного ответа [43]. Для того чтобы вакцина была эффективной, она должна вызывать достаточно устойчивый и специфический иммунный ответ [47]. Для решения этой проблемы требуется включение опухолеспецифических антигенов в геном онколитического вируса с их дальнейшей экспрессией. В опытах на сингенных мышах было установлено, что при экспрессии ТАА вирусом везикулярного стоматита (vesicular stomatitis virus, VSV) происходит индукция кросс-прайминга ТАA-специфического адаптивного Т-клеточного ответа, в отличие от VSV, не экспрессирующего ТАА в той же модели, который провоцировал только противовирусный ответ [13].

Вирус мараба, экспрессирующий меланомаассоциированный антиген допахромной таутомеразы (MG1hDCT), не показал увеличения выживаемости in vivo, а иммунологические анализы показали отсутствие DCTспецифичных ответов CD8+ или CD4+ T-клеток [48]. Однако исследования вируса везикулярного стоматита, экспрессирующего тот же антиген (VSV-hDCT), показали активацию как CD4+, так и CD8+ DCT-специфичные ответы Т-клеток [49]. Авторы проведенных исследований указывают на эффективность MG1-hDCT и VSV-hDCT в качестве прайм-буст вакцинации, о которой будет упомянуто ниже.

\section{Встраивание в геном онколитических вирусов костимулирующего лиганда}

Стимулятором CD40 является лиганд CD40L, который быстро экспрессируется в стрессовых тканях и является одним из наиболее мощных активаторов дендритных клеток, вследствие чего происходит экспрессия молекул MHC I и II и продукция цитокинов, включая IL12, кото- рый способствует индукции Th1 и блокирует активацию Th2 [50], а также увеличивает пролиферацию B- и NKклеток [14]. CD40L эффективен при включении в AdV, но не VSV $[1,2,27]$, так как VSV имеет высокий уровень VSVассоциированной иммуногенности, отвлекая иммунную систему от опухолевых антигенов [50].

Еще в 1998 г. было установлено, что экспрессия CD40L в раковых клетках при зараженности менее 1,5\% опухолевых клеток увеличивает иммуногенность опухоли и выживаемость мышей с нейробластомой после внутриопухолевой инъекции ретровируса с трансгеном CD40L [51].

В апреле 2017 г. было закончено рандомизированное испытание аденовируса со встроенным геном CD4OL (AdCD40L) фазы I/IIa у пациентов с метастатической меланомой. В ходе исследования было выявлено повышение эффекторных Т-клеток по сравнению с T-reg, а также одновременно с этим увеличилось количество рецепторов смерти TNFR1 и TRAIL-R2. Это показывает, что внутриопухолевая инъекция AdCD40L вызывает желаемые иммунные эффекты, которые коррелируют с длительностью выживаемости [52].

\section{Прайм-буст вакцинация (prime-boost vaccination)}

Одним из потенциальных препятствий для приведенных выше подходов является то, что во время виротерапии более иммуногенные вирусные эпитопы могут отвлекать иммунную систему от опухолеспецифических антигенов [13]. Такой процесс принято называть «иммунодоминантностью». Он возникает при введении большого количества вирусных пептидов, которые отвлекают антигенпрезентирующие клетки (АРС) от ТАА [43]. В этой ситуации используется подход «prime-boost»: два гетерологичных вектора со встроенным общим опухольассоциированным антигеном вводят последовательно. Первый вектор (к примеру, аденовирусный) запускает первую линию ТАA-специфичных CD8+ T-клеток, а второй вектор (VSV) применяется дольше, нежели первый, для увеличения количества CD8+ T-клеток до терапевтических уровней [53]. Данный подход позволяет сместить иммунную реакцию в сторону опухолевых антигенов и уменьшить репликацию в здоровых тканях, тем самым повышая эффективность и безопасность [24, 54]. Обнаружено, что при воздействии второго вектора (VSV) на модели мышиной меланомы B16-F10 дополнительно увеличиваются цитотоксическая функция, секреция цитокинов и количество эффекторных Т-клеток, которые образуются в ответ на первое (аденовирусное) введение [55].

Эффективность подхода прайм-буст отмечается и в решении проблемы, связанной с регуляторными Т-лимфоцитами, которые снижают количество антигенпрезентирующих клеток до их взаимодействия с Т-клетками памяти. На той же модели мышиной меланомы (В16) было показано, что благодаря последовательному введению вируса везикулярного стоматита и вируса Мараба увеличивается кросс-презентация антигенов и провоцируется массовое вторичное распространение активированных CD8+ T-клеток, позволяя избежать элиминации антигенпрезентирующих клеток регуляторными Т-лимфоцитами [56].

В 2014 г. Ј. Pol и соавт. [48] сравнили VSV и ослабленный штамм вируса Мараба - MG1 в качестве второго вектора. Опыты показали, что та же доза MG1hDCT вызывала еще более сильный ответ иммунной системы. Помимо CD8+ T-клеток, MG1-hDCT 
Таблица 2. Клинические исследования рекомбинантных онколитических вирусов с повышенной иммуногенностью

\begin{tabular}{|c|c|c|c|}
\hline Трансген & Препарат на основе онколитических вирусов & Стадия & Источник \\
\hline \multirow{4}{*}{ GM-CSF } & $\mathrm{T}-\mathrm{VEC}$ & Одобрено & NCT00769704 \\
\hline & Pexa-Vec (JX594) & III & NCT00554372 \\
\hline & CG0070 & II/III & NCT01438112 \\
\hline & ONCOS-102 & I & NCT01598129 \\
\hline IL2 и TNF $\alpha$ & TILT-123 & Доклиническая & {$[20,57]$} \\
\hline \multirow{3}{*}{ IL12 } & M032-HSV-1 & I & NCT02062827 [1] \\
\hline & Ad5-yCD/mutTKSR39 rep-hIL12 & I & NCT02555397 \\
\hline & AdIL12 & I & NCT00072098 \\
\hline CXCL12/CXCR4 & - & Доклиническая & {$[57]$} \\
\hline \multirow[t]{2}{*}{ HSP } & $\begin{array}{l}\text { Adel55-HSP70 } \\
\text { Adel55-HSP90 } \\
\text { Adel55-cHSF1 }\end{array}$ & Доклиническая & [3] \\
\hline & pNGVL4a-Sig/E7/HSP70 DNA vaccine & I & NCT00788164 \\
\hline \multirow{2}{*}{ TAA } & MG1-hDCT & Доклиническая & {$[48]$} \\
\hline & VSV-hDCT & Доклиническая & {$[6,57]$} \\
\hline \multirow{3}{*}{ CD40 } & \multirow{2}{*}{ AdCD40L } & I & NCT01455259 [52] \\
\hline & & $\mathrm{I} / \mathrm{II}$ & NCT00891748 \\
\hline & Ad-sig-hMUC-1/ecdCD40L & I & NCT02140996 \\
\hline \multirow[b]{2}{*}{ Prime-boost вакцинация } & MG1-hDCT & Доклиническая & {$[48]$} \\
\hline & $\begin{array}{c}\text { MG1MA3 } \\
\text { AdMA3 }\end{array}$ & $\mathrm{I} / \mathrm{II}$ & NCT02285816 \\
\hline
\end{tabular}

также способствовал повышению системного CD4+ Т-клеточного ответа после внутривенного введения. Эксперименты показали увеличение продолжительности жизни наблюдаемых животных, а полная ремиссия была достигнута в $21,4 \%$ случаев [48]. На данный момент проводится клиническое исследование фазы II с использованием векторов аденовируса и Марабы, экспрессирующих опухольассоциированные антигены MAGE-A3 [36]. Релевантные клинические исследования перечисленных подходов онколитической иммунотерапии приведены в табл. 2.

\section{Встраивание в геном онколитических вирусов} ингибиторов контрольных точек иммунитета

В 2017 г. было проведено исследование фазы Ib комбинированного лечения меланомы при внутриопухолевом введении T-Vec и пембролизумаба (моноклональное антитело, селективно блокирующее взаимодействие между PD-1 и его лигандами PD-L1 и PD-L2), что привело к значительному повышению уровня CD8 ${ }^{+}$ T-лимфоцитов, усилению экспрессии белка PDL1 и интерферона $\gamma$ в опухоли. При этом отмечался значительный уровень подтвержденного объективного ответа, который составил $62 \%$, полный показатель ответа - $33 \%$ по критериям иммунного ответа, а профиль токсичности не превышал показателей при монотерапии данными препаратами [57].

В связи с показанной эффективностью предыдущего исследования в настоящее время исследуется и альтернативный подход - создание онколитического вируса, несущего ген ингибитора контрольных точек иммунитета, наличие которого, как предполагают ученые, сможет снизить токсичность, наблюдаемую при системном применении чекпоинт-ингибиторов [58]. К сожалению, данный метод опробован только на мышах. М. Bartee и соавт. создали онколитический миксомавирус, кодирующий PD1, и получили значительную эффективность и меньшую токсичность, чем при использовании данного вируса или пембролизумаба по отдельности [59].

\section{Заключение}

Онколитические вирусы, возможно, могут стать потенциальными терапевтическими агентами с широким набором функций, сочетая в себе свойства «раковых киллеров», антиангиогенных агентов, векторов генной терапии, локальных адъювантов, стимулирующих иммунные реакции. Такая полифункциональность делает онколитические вирусы уникальной платформой для реализации различных подходов в борьбе против рака. Наиболее перспективной стратегией лечения опухолей в настоящее время можно считать использование онколитических вирусов как иммунотерапевтических агентов.

Тем не менее до сих пор одной из главных проблем, ограничивающих применение онколитических вирусов, остается их элиминация иммунными клетками организма до проникновения в клетки опухоли. Кроме того, усиленный цитокинами иммунитет может ингибировать репли- 
кацию вируса и тем самым предотвращать эффективный лизис опухолевых клеток. Одним из подходов решения данной проблемы может быть экспрессия онколитическими вирусами хемокинов вместо цитокинов, поскольку первые влияют на общий иммунный ответ без прямого противовирусного воздействия.

Предстоит также ускорить исследование различных способов эффективной системной доставки онколитических вирусов в раковые клетки и методов разрушения микросреды опухоли, основываясь на биологических свойствах данных терапевтических агентов.

Не исключается также возможность использования онколитических вирусов и ингибиторов иммунных контрольных точек (чекпоинтов) как в комбинации, так и при генной модификации самого вируса, что позволит также во много раз повысить противоопухолевую эффективность терапии.

Таким образом, несмотря на медленный прогресс и незначительные успехи в недалеком прошлом, модификация онколитических вирусов в качестве иммунотерапевтических агентов потенциально имеет перспективы в направлении создания полноценных, высокоэффективных препаратов против злокачественных новообразований.

\section{Дополнительная информация}

Источник финансирования. Поисково-аналитическая работа и подготовка статьи проведены на личные средства авторского коллектива.

Конфликт интересов. Авторы данной статьи подтвердили отсутствие конфликта интересов, о котором необходимо сообщить.

Участие авторов: Глухов А.И. - научный руководитель, научная коррекция текста, заключительная редакция; Сивохин Д.А. - написание стратегий усиления иммуногенности онколитических вирусов, аннотации, перевод аннотации, заключения, редакция всего текста статьи, анализ источников литературы, оформление библиографии, подача статьи в журнал; Серяк Д.А. - разработка концепции и дизайна обзора, критериев включения и исключения источников литературы в обзор; Родионова Т.С. - написание механизмов вирусного онколиза и селективности действия онколитических вирусов, аннотации; Камынина М.И. - написание введения обзора, первичный отбор литературных источников.

\section{ЛИТЕРАТУРА}

1. Zhang S. Progress in cancer immunotherapy. Adv Exp Med Biol. 2016;909:v-vi. doi: 10.1007/978-94-017-7555-7.

2. Chiocca EA, Rabkin SD. Oncolytic viruses and their application to cancer immunotherapy. Cancer Immunol Res. 2014;2(4):295-300. doi: 10.1158/2326-6066.CIR-14-0015.

3. Fukuhara H, Ino Y, Todo T. Oncolytic virus therapy: a new era of cancer treatment at dawn. Cancer Sci. 2016;107(10):1373-1379. doi: $10.1111 /$ cas. 13027

4. Tsun A, Miao XN, Wang CM, Yu DC. Oncolytic immunotherapy for treatment of cancer. Adv Exp Med Biol. 2016;909:241-283. doi: 10.1007/978-94-017-7555-7_5.

5. Cassel WA, Murray DR, Phillips HS. A phase II study on the postsurgical management of stage II malignant melanoma with a Newcastle disease virus oncolysate. Cancer. 1983;52(5):856860. doi: 10.1002/1097-0142(19830901)52:5<856::aidcncr2820520519>3.0.co;2-4.

6. Hammerich L, Bhardwaj N, Kohrt HE, Brody JD. In situ vaccination for the treatment of cancer. Immunotherapy. 2016;8(3):315-330. doi: 10.2217 /imt.15.120.

7. Doninga S, Strēle I, Proboka G, et al. Adapted ECHO-7 virus rigvir immunotherapy (oncolytic virotherapy) prolongs survival in melanoma patients after surgical excision of the tumour in a retrospective study. Melanoma Res. 2015;25(5):421-426. doi: 10.1097/ CMR.0000000000000180.

8. Andtbacka RH, Kaufman HL, Collichio F, et al. Talimogene laherparepvec improves durable response rate in patients with advanced melanoma. J Clin Oncol. 2015;33(25):2780-2788. doi: 10.1200/ JCO.2014.58.3377.

9. Nobel Foundation. The 2018 Nobel Prize in Physiology or Medicine is being awarded jointly to James P. Allison and Tasuku Honjo for their discovery of cancer therapy by inhibition of negative immune regulation [Internet]. ScienceDaily, 2018 [cited 2018 October 1]. Available from: https://www.sciencedaily.com/releases/2018/10/181001093316.htm.

10. Aurelian L. Oncolytic virotherapy: the questions and the promise. Oncolytic Virother. 2013;2:19-29. doi: 10.2147/OV.S39609.

11. Shashkova EV, May SM, Doronin K, Barry MA. Expanded anticancer therapeutic window of hexon-modified oncolytic adenovirus. Mol Ther. 2009;17(12):2121-2130. doi: 10.1038/mt.2009.217.

12. Chaurasiya S, Warner S. Viroimmunotherapy for colorectal cancer : clinical studies. Biomedicines. 2017;5(1). pii: E11. doi: 10.3390/ biomedicines5010011.

13. Elsedawy NB, Russell SJ. Oncolytic vaccines. Expert Rev Vaccines. 2013;12(10):1155-1172. doi: 10.1586/14760584.2013.836912.

14. Rajani KR, Vile RG. Harnessing the power of onco-immunotherapy with checkpoint inhibitors. Viruses. 2015;7(11):5889-5901. doi: $10.3390 / \mathrm{v} 7112914$.
15. Breitbach CJ, Lichty BD, Bell JC. Oncolytic viruses: therapeutics with an identity crisis. EBioMedicine. 2016;9:31-36. doi: 10.1016/j. ebiom.2016.06.046.

16. Simovic B, Walsh SR, Wan Y. Mechanistic insights into the oncolytic activity of vesicular stomatitis virus in cancer immunotherapy. Oncolytic Virotherapy. 2015;4:157-167. doi: 10.2147/ OV.S66079.

17. Schirrmacher V. Oncolytic Newcastle disease virus as a prospective anti-cancer therapy. A biologic agent with potential to break therapy resistance. Expert Opin Biol Ther. 2015;15(12):1757-1771. doi: 10.1517/14712598.2015.1088000.

18. Fountzilas C, Patel S, Mahalingam D. Review: oncolytic virotherapy, updates and future directions. Oncotarget. 2015;8(60):102617102639. doi: 10.18632/oncotarget. 18309.

19. Havunen R, Siurala M, Sorsa S, et al. Oncolytic adenoviruses armed with tumor necrosis factor alpha and interleukin-2 enable successful adoptive cell therapy. Mol Ther Oncolytics. 2017;4:77-86. doi: 10.1016/j.omto.2016.12.004.

20. Guo ZS, Liu Z, Bartlett DL. Oncolytic immunotherapy: dying the right way is a key to eliciting potent antitumor immunity. Front Oncol. 2014;4:74. doi: 10.3389/fonc.2014.00074.

21. Simon EJ, Howells MA, Stuart JD, Boehme KW. Serotype-specific killing of large cell carcinoma cells by reovirus. Viruses. 2017;9(6). pii: E140. doi: 10.3390/v9060140.

22. De Munck J, Binks A, McNeish IA, Aerts JL. Oncolytic virusinduced cell death and immunity: a match made in heaven? J Leukoc Biol. 2017;102(3):631-643. doi: 10.1189/jlb.5RU0117-040R.

23. Tazawa H, Kuroda S, Hasei J, et al. Impact of autophagy in oncolytic adenoviral therapy for cancer. Int J Mol Sci. 2017;18(7):1-13. doi: $10.3390 /$ ijms 18071479 .

24. Woller N, Gürlevik E, Ureche C-I, et al. Oncolytic viruses as anticancer vaccines. Front Oncol. 2014;4:188. doi: 10.3389/ fonc.2014.00188.

25. Colunga AG, Laing JM, Aurelian L. The HSV-2 mutant DeltaPK induces melanoma oncolysis through nonredundant death programs and associated with autophagy and pyroptosis proteins. Gene Ther. 2010;17(3):315-327. doi: 10.1038/gt.2009.126.

26. Bartlett DL, Liu Z, Sathaiah M, et al. Oncolytic viruses as therapeutic cancer vaccines. Mol Cancer. 2013;12(1):103. doi: 10.1186/14764598-12-103.

27. Aurelian L. Oncolytic viruses as immunotherapy: progress and remaining challenges. Onco Targets Ther. 2016;9:2627-2637. doi: 10.2147/OTT.S63049.

28. Ahmad U, Ahmed I, Keong YY, et al. Inhibitory and apoptosisinducing effects of Newcastle disease virus strain AF2240 on mammary carcinoma cell line. Biomed Res Int. 2015;2015:127828. doi: $10.1155 / 2015 / 127828$. 
29. Кешелава В.В. Использование иммуностимулирующего действия онколитического вируса болезни Ньюкасла при лечении рака репродуктивных органов // Эпидемиология и вакиинопрофилактика. - 2010. - №5 - C. 86-93. [Keshelava VV. Use immunopotentiating activity of oncolytic Newcastle disease virus to treatment the reproductive organs cancer. Epidemiology and Vaccine Prevention. 2010;(5):86-93. (In Russ).]

30. Gollamudi R, Ghalib MH, Desai KK, et al. Intravenous administration of reolysin, a live replication competent RNA virus is safe in patients with advanced solid tumors. Invest New Drugs. 2010;28(5):641-649. doi: 10.1007/s10637-009-9279-8.

31. Galanis E, Markovic SN, Suman VJ, et al. Phase II trial of intravenous administration of reolysin (reovirus serotype-3-dearing strain) in patients with metastatic melanoma. Mol Ther. 2012;20(10):19982003. doi: $10.1038 / \mathrm{mt} .2012 .146$.

32. Carew JS, Espitia CM, Zhao W, et al. Oncolytic reovirus inhibits angiogenesis through induction of CXCL10/IP-10 and abrogation of HIF activity in soft tissue sarcomas. Oncotarget. 2017;8(49):8676986783. doi: 10.18632 /oncotarget. 21423.

33. Mahalingam D, Goel S, Aparo S, et al. A phase II study of pelareorep (REOLYSIN) in combination with gemcitabine for patients with advanced pancreatic adenocarcinoma. Cancers (Basel). 2018;10(6):1-12. doi: 10.3390/cancers 10060160.

34. Jonker DJ, Tang PA, Kennecke H, et al. A Randomized phase two study of FOLFOX6/bevacizumab with or without pelareorep in patients with metastatic colorectal cancer: IND.210, a Canadian Cancer Trials Group Trial. Clin Colorectal Cancer. 2018;17(3):231239.e7. doi: 10.1016/j.clcc.2018.03.001.

35. Vacchelli E, Martins I, Eggermont A, et al. Trial watch. Oncoimmunology. 2012;1(9):1557-1576. doi: 10.4161/onci.22428.

36. Aitken A, Roy D, Bourgeois-Daigneault M-C. Taking a stab at cancer; Oncolytic virus-mediated anti-cancer vaccination strategies. Biomedicines. 2017;5(1). pii: E3. doi: 10.3390/biomedicines5010003.

37. Heo J, Reid T, Ruo L, et al. Randomized dose-finding clinical trial of oncolytic immunotherapeutic vaccinia JX-594 in liver cancer. Nat Med. 2013;19(3):329-336. doi: 10.1038/nm.3089.

38. Breitbach CJ, Arulanandam R, De Silva N, et al. Oncolytic vaccinia virus disrupts tumor-associated vasculature in humans. Cancer Res. 2013;73(4):1265-1275. doi: 10.1158/0008-5472.CAN-12-2687.

39. Thorne S, Sampath P. Novel therapeutic strategies in human malignancy: combining immunotherapy and oncolytic virotherapy. Oncolytic Virotherapy. 2015;4:75. doi: 10.2147/OV.S54738.

40. Thomas ED, Meza-Perez S, Bevis KS, et al. IL-12 Expressing oncolytic herpes simplex virus promotes anti-tumor activity and immunologic control of metastatic ovarian cancer in mice. $J$ Ovarian Res. 2016;9(1):70. doi: 10.1186/s13048-016-0282-3.

41. Patel D, Foreman P, Nabors B, et al. Design of a phase I clinical trial to evaluate M032, a genetically engineered HSV-1 expressing IL-12, in patients with recurrent/progressive glioblastoma multiforme, anaplastic astrocytoma, or gliosarcoma. Hum Gene Ther Clin Dev. 2016;27(2):69-78. doi: 10.1089/hum.2016.031.

42. Gil M, Seshadri M, Komorowski MP, et al. Targeting CXCL12/ CXCR4 signaling with oncolytic virotherapy disrupts tumor vasculature and inhibits breast cancer metastases. Proc Natl Acad Sci. 2013;110(14):E1291-300. doi: 10.1073/pnas. 1220580110.

43. Hammerich L, Binder A, Brody JD. In situ vaccination: cancer immunotherapy both personalized and off-the-shelf. Mol Oncol. 2015;9(10):1966-1981. doi: 10.1016/j.molonc.2015.10.016.
44. Fan R, Wang C, Wang Y, et al. Enhanced antitumoral efficacy and immune response following conditionally replicative adenovirus containing constitutive HSF1 delivery to rodent tumors. J Transl Med. 2012;10(1):101. doi: 10.1186/1479-5876-10-101.

45. Li J-L, Liu H-L, Zhang X-R, et al. A phase I trial of intratumoral administration of recombinant oncolytic adenovirus overexpressing HSP70 in advanced solid tumor patients. Gene Ther. 2009;16(3):376382. doi: 10.1038/gt.2008.179.

46. Hou W, Sampath P, Rojas JJ, Thorne SH. Oncolytic virusmediated targeting of PGE2 in the tumor alters the immune status and sensitizes established and resistant tumors to immunotherapy. Cancer Cell. 2016;30(1):108-119. doi: 10.1016/j.ccell.2016.05.012.

47. Mould RC, AuYeung AW, van Vloten JP, et al. Enhancing immune responses to cancer vaccines using multi-site injections. Sci Rep. 2017;7(1):8322. doi: 10.1038/s41598-017-08665-9.

48. Pol JG, Zhang L, Bridle BW, et al. Maraba virus as a potent oncolytic vaccine vector. Mol Ther. 2014;22(2):420-429. doi: 10.1038/mt.2013.249.

49. Bridle BW, Boudreau JE, Lichty BD, et al. Vesicular stomatitis virus as a novel cancer vaccine vector to prime antitumor immunity amenable to rapid boosting with adenovirus. Mol Ther. 2009;17(10):1814-1821. doi: 10.1038/mt.2009.154.

50. Galivo F, Diaz RM, Thanarajasingam U, et al. Interference of CD40L-mediated tumor immunotherapy by oncolytic vesicular stomatitis virus. Hum Gene Ther. 2010;21(4):439-450. doi: 10.1089/ hum.2009.143.

51. 46.Loskog A. Immunostimulatory gene therapy using oncolytic viruses as vehicles. Viruses. 2015;7(11):5780-5791. doi: 10.3390/ v7112899.

52. Schiza A, Wenthe J, Mangsbo S, et al. Adenovirus-mediated CD40L gene transfer increases teffector/tregulatory cell ratio and upregulates death receptors in metastatic melanoma patients. $J$ Transl Med. 2017;15(1):79. doi: 10.1186/s12967-017-1182-z.

53. Swift SL, Stojdl DF. Big data offers novel insights for oncolytic virus immunotherapy. Viruses. 2016;8(2):14-17. doi: 10.3390/v8020045.

54. Bridle BW, Stephenson KB, Boudreau JE, et al. Potentiating cancer immunotherapy using an oncolytic virus. Mol Ther. 2010;18(8):1430-1439. doi: 10.1038/mt.2010.98.

55. Bridle BW, Clouthier D, Zhang L, et al. Oncolytic vesicular stomatitis virus quantitatively and qualitatively improves primary CD8+ T-cell responses to anticancer vaccines. Oncoimmunology. 2013;2(8):e26013. doi: 10.4161/onci.26013.

56. Bridle BW, Nguyen A, Salem O, et al. Privileged antigen presentation in splenic B cell follicles maximizes T cell responses in prime-boost vaccination. J Immunol. 2016;196(11):4587-4595. doi: 10.4049/ jimmunol.1600106.

57. Ribas A, Dummer R, Puzanov I, et al. Oncolytic virotherapy promotes intratumoral $\mathrm{T}$ cell infiltration and improves anti-PD-1 immunotherapy. Cell. 2017;170(6):1109-1119.e10. doi: 10.1016/j. cell.2017.08.027.

58. Kleinpeter P, Fend L, Thioudellet C, et al. Vectorization in an oncolytic vaccinia virus of an antibody, a Fab and a scFv against programmed cell death-1 (PD-1) allows their intratumoral delivery and an improved tumor-growth inhibition. Oncoimmunology. 2016;5(10):e1220467. doi: 10.1080/2162402X.2016.1220467.

59. Bartee MY, Dunlap KM, Bartee E. Tumor-localized secretion of soluble PD1 enhances oncolytic virotherapy. Cancer Res. Cancer Res. 2017;77(11):2952-2963. doi: 10.1158/0008-5472.CAN-16-1638.

\section{КОНТАКТНАЯ ИНФОРМАЦИЯ}

*Глухов Александр Иванович, д.б.Н., профессор [Alexander Ivanovich Glukhov, PhD, professor]

Адрес: 119991, Москва, ул. Трубецкая, д. 8, стр. 2 [address: 119991, 8-2 Trubetskaya str., Moscow, Russia]; e-mail: aiglukhov1958@gmail.com, SPIN-код: 3926-8485, ORCID: https://orcid.org/0000-0002-7371-1183

Сивохин Дмитрий Алексеевич [Dmitrii A. Sivokhin]; e-mail: dr.sivokhin@gmail.com, SPIN-код: 8362-3570, ORCID: https://orcid.org/0000-0001-7341-1167

Серяк Дарья Александровна [Daria A. Seriak]; e-mail: daria.seriak@gmail.com, SPIN-код: 8395-4172, ORCID: https://orcid.org/0000-0003-3884-9256

Родионова Татьяна Сергеевна [Tatiana S. Rodionova]; e-mail: tata92176@gmail.com SPIN-код: 5948-8248, ORCID: https://orcid.org/0000-0003-0336-3459

Камынина Маргарита Игоревна [Margarita I. Катуnina]; e-mail: margaret.kamynina@gmail.com, SPIN-код: 9756-5856, ORCID: https://orcid.org/0000-0001-8093-8151 